\title{
Popular marathons, half marathons, and other long distance runs: recommendations for medical support
}

\author{
RECOMMENDATIONS OF A CONSENSUS CONFERENCE*
}

With the boom in jogging, the character of marathon and other long distance races has changed dramatically. A few years ago there were a few races for experienced club athletes who had usually had many years of athletics behind them and did not expect much in the way of facilities let alone medical support. In the past few years the number of races has increased almost logarithmically, reaching a total in 1983 in Great Britain of 136 full marathons ( 26 miles 385 yards, $42.2 \mathrm{~km}$ ) with an average field of 1000 runners, but with fields as high as 20000 in the London Marathon and even more for the Great North Run (half marathon).

This boom in events has been associated with a change in the participants. They are now very largely novice runners unaffiliated to clubs, many of them (often as many as half)

-These recommendations are the consensus view of a conference held in February 1984 and sponsored by the Fitness and Health Advisory Group (FHAG) of the Sports Council and the Health Education Council.

Organiser and editor, Dr Dan Tunstall Pedoe, Cardiac Department, St Bartholomew's Hospital, London EC1A 7BE; medical director, London Marathon; chairman British Association of Sport and Medicine.

Participants: Dr R Brotherwood, London Marathon, St John Ambulance Brigade; Dr P' Carson, cardiologist, Potteries Marathon, FHAG, Sports Council; Mr M Collins, Sports Council; Dr A R Maryon Davis, Health Education Council; Mr Andy Etchells, editor, Running Magazine; Mr John Fullard, Great North Run, British Red Cross Society; Mr Ralph Graham, London Marathon, Podiatry Association; Dr R W Green, general practitioner, FHAG, Sports Council; Miss Mary Harman, research student, Aberdeen; Mrs R Macdonald, London Marathon, Physiotherapist, ACPSM; Dr R Maughan, Aberdeen Marathon, physiologist, Aberdeen University; Professor J N Morris, chairman FHAG, Sports Council, London School of Hygiene and Tropical Medicine; Dr A Porter, general practitioner, Camberley; Mr Richard Sainsbury, medical director Great North Run; Dr Craig Sharp, physiologist, University of Birmingham; Dr P Sperryn, consultant in physical medicine, British Association of Sport and Medicine; Mrs C M Stretton, nursing tutor, London Marathon, St John Ambulance; Dr Clyde Williams, physiologist, University of Technology, Loughborough; Dr B Williams, Medical Care Research Unit, University of Sheffield; Dr A Young, consultant in rehabilitation, scientific secretary FHAG, Sports Council. attempting the distance for the first time and expecting and needing a high level of logistic and medical support.

These recommendations are based on experience of these popular events and are directed towards the medical support teams for these events, many of whom may have little knowledge of what to expect. They are less appropriate for the smaller field races for dedicated club runners which still exist alongside the popular events. The medical advice sheet and advice sheet for first aiders (see boxes) are based on those used in the London Marathon by its medical director.

\section{Organisation of medical support: the medical director}

Medical support for a marathon or mass run is often recruited late in the planning. Yet medical input is required from the very start to ensure adequate medical services and a safe route for evacuating casualties. There should be a qualified medical officer concerned in the planning of the race and its route at an early stage. Ideally he or she should have a direct interest in running and be well known locally. A doctor with an interest in running is more likely to obtain the cooperation of the runners and can more easily deal with press and radio interviews on the event. A hospital doctor may well be best placed to call on local facilities.

The medical director should coordinate the work of the Red Cross, St John Ambulance Brigade, Territorial Army Medical Corps, local doctors with an interest in sports medicine, podiatrists (or state registered chiropodists), and physiotherapists. The medical director should plan the first aid points and the medical facility at the finish with them and with the marathon organising committee, order the necessary medical supplies, and be able to advise the marathon director on the safety of the course and provision of medical facilities.

When a qualified medical officer is not available a nurse, physiotherapist, podiatrist, or sports scientist with an interest in running could be appointed as medical coordinator, but he or she would have to involve a doctor from one of the voluntary organisations at an early stage.

The other duties of the medical director or coordinator are described below. 


\section{Entrants}

Although running has a very low morbidity and extremely low mortality the medical director may reduce the risks by issuing a medical advice sheet, which should be sent to each entrant at the time his entry is accepted.

Medical advice sheet-The advice sheet performs several functions. The medical director cannot take individual responsibility for the health of everyone who applies to run and he cannot reasonably suggest that all applicants obtain a medical certificate certifying their fitness to run. He therefore has to warn potential runners of the type of medical problems that would make it hazardous for them to run. A legal liability waiver is usually incorporated within the runner's application form. This makes it plain that runners take responsibility for their own welfare and fitness to take part and, along with the medical advice sheet, suggests that if necessary they should seek medical advice. The advice sheet is important in reinforcing the runner's responsibility to himself or herself and emphasises that no one should run if he feels unwell. A modified version of the London Marathon medical advice sheet is printed in the box.

Age of entry-If the race is run under the rules of the Amateur Athletic Association or Women's Amateur Athletic Association there are a range of age limits for cross country and road races of different distances and for each sex, but for an open half marathon all entrants must be over 17 on the day of the race and for a marathon all entrants must be over 18. Many younger entrants can undoubtedly complete these distances, but there is considerable concern about the possible deleterious effects on growing adolescents of long distance running on roads, as well as the potential for ambitious parents to push their children too hard. Shorter races run at a greater speed are probably better preparation for marathon racing than marathon races themselves.

Wheel chair entrants, although not strictly pedestrians (and therefore ineligible under Amateur Athletics Association and international rules), have been allowed in many popular marathons and have proved very popular with the crowds. Racing machines with bicycle wheels can reach $\mathbf{4 0} \mathrm{mph}$ on a downhill stretch, and if they are not properly controlled may injure tired, slow moving runners and upend race marshals, as well as annoy many others with their compressed gas powered klaxons. The course itself must be safe for wheelchairs, with no steep hills or very sharp bends, and if wheel chair competitors are being considered their own association can be approached for advice. Ideally toilets for the disabled should be provided at the start and the finish, the wheel chair competitors should start before the runners, and the course should be wide enough along its length for runners and wheelchairs to pass each other easily. The runners need to be warned of the presence of wheelchairs and, to judge from the last London Marathon, the wheel chair competitors need to be advised to show consideration to tired runners and race marshals.

Registration-Sick or unfit runners should be encouraged to hand in their race acceptance cards in exchange for guaranteed entry the following year. This cuts down the number of casualties. Runners should be encouraged to reread their medical advice sheet.

\section{Detailed planning}

\section{THE START}

Assembling a large number of runners is logistically difficult, and they can become very cold while waiting. The runners should be without their track suits and other protection against the weather for as short a time as possible before the start. There should be adequate toilets and adequate last minute drinks. The exit from the start should be such that there are no sudden bottle necks or rish. 3 of people falling and becoming trampled.

\section{THE COURSE}

The course should have a reasonable surface with no unexpected hazards such as kerbs or bollards. If these cannot be removed they must be well advertised so chat a runner in a pack does not trip or run into an unexpected obstruction. The route should be wide enough to accommodate the bulge of the field (modal time runners) and all ow them to pass each other safely.

Drink stations are of great medical importance but are also potential hazards. Runners may collide with others stopping for a drink or slip on discarded paper cups or orange peel. Drinking frequently, especially in hot weather, reduces casualties. The American College of Sports Medicine quite rightly recommends drinks stations every $3-4 \mathrm{~km}$ (2-2.5 miles) for all races of $16 \mathrm{~km}$ (10 miles) or more. This is more frequently than the Amateur Athletics Association sanctions for races of under marathon distance. Fluid replacement is probably more beneficial in protecting the runner early in the race, and a large number of drink stations near the end of the race may be of more psychological than physical benefit. Sponging is of less real benefit. Water is the most important form of liquid replacement and should be available at all refreshment points. Glucose electrolyte drinks must be made up to the dilution recommended by the manufacturer for the ambient temperature and only made up on the day of the race as they are an excellent bacterial culture medium. Runners should be told to throw their cups to the side of the route, and the cups should be crushable. The cups should be handed to the runners and there should be sufficient staff to do this. The drink stations should be well marked: which side of the road they are on and which drinks are available must be clearly shown. Runners not wanting a drink must have a clear route through.

First aid stations should ideally be sited 50-100 metres downstream of the drink stations so that runners know where to look for them. They should have communication with an ambulance if none is available on site and they should be sited so that casualties can be evacuated if necessary. They should offer some form of shelter to cold wet runners who may want to wait for the pick up bus. The number of first aid stations and the level of staffing depends on the number of competitors, but for marathons first aid points should be no more than five miles apart and for half marathons no more than three miles. Looped courses allow considerable economy in drinks and aid stations.

Toilets-Some runners drink coffee at the start after overhydrating themselves and have an urgent need to micturate as they have a powerful diuresis. Others get "runners trots." A few well marked toilets on the route are therefore essential to avoid embarrassing spectacles for the spectators.

The finish-A runner finishing a marathon should be able to find his or her clothes and change into warm dry clothing as soon as possible, rehydrate, have something to eat, and sit down under cover in a designated "recovery area" until he is ready to make a safe journey home.

The medical director should plan a medical area which not only helps the stricken runner but also protects the local hospitals from a sudden rush of "self induced injury."

\section{FINISH MEDICAL AREA}

The medical area at the finish should be close to the finish line but also accessible for ambulances and also for runners who collapse as much as $\mathbf{2 0}$ minutes after finishing. This delayed collapse occurs when the intense vasoconstriction that maintains the blood pressure in many hypovolaemic, cyanosed runners relaxes before the runner has had time to rehydrate himself. The medical area should be large enough to deal with up to $5 \%$ ("total throughput") of the race entry of a marathon and proportionately more in shorter "fun runs." Adequate heating and lighting are essential.

Camp beds or equivalent (150 for the London Marathon) and an equal number of chairs for walking wounded; vomit bowls; toilets in the medical area; plenty of fresh water, preferably on tap; waste buckets; dressings; and ice are all essential. There should be enough space between the beds for physiotherapists and podiatrists to work. A guarded entry to the medical area is essential, to keep out distraught relatives searching for their lost runner and to keep out press and TV reporters and cameramen. All medical staff should wear distinctive clothing or have entry passes, and one way in and one out simplifies keeping a log of the casualties.

Triage of the casualties and allocation of the casualties to designated areas for physiotherapy (severe cramp), podiatry (blisters and subungual haematomas), and constitutional problems such as diarrhoee or vomiting is helpful. The medical area should allow sufficient privacy between the sexes so that runners' wet clothing can be completely removed and rectal temperatures taken without undue embarrassment.

Intensive care-An intensive care section in the medical area is essential for the rare runner who requires intravenous fluids or resuscitation. A defibrillator, portable oxygen, sucker, and so on, are needed. Hatstands make useful drip stands.

Information-An information desk should be kept informed of the running numbers of people in the medical area and the numbers and names of anyone sent to hospital. Relatives can become extremely 
distressed if they cannot locate their loved ones and can completely overrun the medical area if allowed to do so.

Transport-Transport may need to be sent to collect runners from hospitals or other sites on the course to bring them back to the finish. The medical director should always be in contact and have access to transport for this purpose.

The management of medical problems associated with marathon running is described in the first aid advice sheet (see box). It also describes the classification of problems into social contacts and casualties.

\section{LOCAL HOSPITALS}

If adequate medical support is available at the finish it is very unusual to have to send a casualty to hospital (for haematemesis, cardiac arrest). The vast majority of collapsed runners recover very quickly with oral rehydration, and the need for intravenous therapy alone is not a necessary indication for admission. Only two runners out of 600 in the finish medical area of the 1983 London Marathon were sent to hospital, both for gastrointestinal bleeding. The rest were all speedily treated and reunited with their clothes and money and their relatives or friends. Admission to hospital usually means separation from all of these. Nevertheless, local hospitals need to be warned about the event and what they should do with ill clad, moneyless runners when they are fit to be discharged from casualty.

\section{SHOULD A MARATHON EVER BE CALLED OFF ?}

Occasionally environmental conditions can be particularly hazardous for marathon or long distance running. With runners adequately protected against the cold races can be held in subfreezing conditions, but if black ice or freezing fog would make it hazardous for the lead car to go round the course then it would be foolhardy to hold the race. As races are more common in the summer, it is more likely, however, that the day may be particularly hot.

We support the recommendations of the American College of Sports Medicine that distance races ( $>16 \mathrm{~km}$ or 10 miles) should not be conducted when the wet bulb temperature globe temperature exceeds $28^{\circ} \mathrm{C}\left(82 \cdot 4^{\circ} \mathrm{F}\right)$. During periods of the year when the daylight dry bulb temperature often exceeds $27^{\circ} \mathrm{C}\left(80^{\circ} \mathrm{F}\right)$ distance races should be conducted before 900 am or after $400 \mathrm{pm}$. These conditions are not commonly met in Britain but did exist last summer. If there is a heat wave the race director must be told that to contravene these recommendations would be foolhardy and that some runners would suffer heat stroke.

\section{WHO CAN STOP A RUNNER ?}

In most events the medical officer has the right to pull out a competitor. A mass marathon cannot be covered by one person and it is therefore the duty of race marshals and first aiders to dissuade confused and sometimes aggressive runners from continuing if they are patently not aware of their surroundings and are disorientated. Every confused runner must have a rectal temperature taken as cases of hyperpyrexia çan occur even on mild days in mass runs and the physical signs can be most misleading.

\section{Stafi}

First aiders-Because of the large numbers of runners the bulk of the casualties have to be handled by first aiders, and in Britain these are most easily cbtained through St John Ambulance Brigade or the Red Cross. For the London Marathon an advice sheet was produced by the Medical Director and this has formed the basis of the advice on first aid and casualty management printed here (see box). Copies were sent to St John Ambulance Brigade and to the physiotherapists and podiatrists helping them. Copies and explanatory letters were also sent to the hospitals on the route of the marathon, who were also warned of the time of the marathon.

Physiotherapists, podiatrists, and doctors-Physiotherapists are invaluable for dealing with muscular problems, particularly cramp. They need adequate space to work and often need ice. Podiatrists also give an invaluable service in dealing with foot and ankle problems. They need electrical power outlets for their portable nail drills. Both these specialist groups can be contacted through their professional associations (see Appendix). It is important to use qualified state registered practitioners, and if a local contact is not known the organisations listed will supply names of local recognised practitioners. Doctors are needed particularly at the finish for triage and intensive care. Doctors accustomed to resuscitation and intravenous therapy are needed, but they may need to be restrained from overtreating. For example, the routine use of antiinflammatory drugs in all casualties is potentially hazardous.

Staff requirements-It is difficult to predict workload and exact requirements, but overall and allowing for meal breaks and short rest breaks the following numbers (based on the London Marathon) would seem reasonable. For each 1000 runners there should be 20 first aiders, three nurses, one physiotherapist, one podiatrist (or state registered chiropodist), and one doctor. Some economies can be made if the course is a loop.

Volunteers themselves need to be looked after and they need food and drink and somewhere to relax, as they may be on duty for many hours. The medical budget should cover their expenses both for travel and dressings, etc.

\section{Appendix}

The following organisations can give advice.

Association of Chartered Physiotherapists in Sports Medicine: $\mathrm{Mr}$ D P Chapman, Half Moon Place, Burwash Road, Heathfield, East Sussex.

British Association of Sport and Medicine: Mr D P Chapman, Half Moon Place, Burwash Road, Heathfield, East Sussex.

British Sports Association for the Disabled: Mrs J Ward, 5 Rushett Close, Long Ditton, Surrey.

The Podiatry Association: The Secretary, Swaynes Cottage, Fore Street, Weston, Nr Hitchin, Herts.

Details of deaths during marathon or mass runs are being collected by Dr D S Tunstall Pedoe, Cardiac Department, St Bartholomew's Hospital, London EC1A 2BE.

Requests for reprints should be sent to Dr Tunstall Pedoe or to the Sports Council or Health Education Council. 